\title{
Synthesis of Glutathione Coated Quantum Dots
}

\author{
Jana Chomoucka ${ }^{1,3}$, Jana Drbohlavova1,3, Petra Businova ${ }^{1}$, \\ Marketa Ryvolova 2,3, Vojtech Adam ${ }^{2,3}$, Rene Kizek ${ }^{2,3}$ and Jaromir Hubalek ${ }^{1,3}$ \\ ${ }^{1}$ Department of Microelectronics, Faculty of Electrical Engineering and Communication, \\ Brno University of Technology \\ ${ }^{2}$ Department of Chemistry and Biochemistry, Faculty of Agronomy, \\ Mendel University in Brno \\ ${ }^{3}$ Central European Institute of Technology, Brno University of Technology \\ Czech Republic
}

\section{Introduction}

QDs play an important role mainly in the imaging and as highly fluorescent probes for biological sensing that have better sensitivity, longer stability, good biocompatibility, and minimum invasiveness. The fluorescent properties of QDs arise from the fact, that their excitation states/band gaps are spatially confined, which results in physical and optical properties intermediate between compounds and single molecules. Depending on chemical composition and the size of the core which determines the quantum confinement, the emission peak can vary from UV to NIR wavelengths (400-1350 nm). In other words, the physical size of the band gap determines the photon's emission wavelength: larger QDs having smaller band gaps emit red light, while smaller QDs emit blue light of higher energy (Byers \& Hitchman 2011). The long lifetime in the order of 10-40 ns increases the probability of absorption at shorter wavelengths and produces a broad absorption spectrum (Drummen 2010).

The most popular types of QDs are composed of semiconductors of periodic group II-VI (CdTe, CdSe, CdS, ZnSe, ZnS, PbS, PbSe, PbTe, SnTe), however also other semiconductor elements from III-V group such as In, Ga, and many others can be used for QDs fabrication (e.g. InP) (Wang \& Chen 2011). Particularly, much interest in nanocrystals is focused on the core/shell structure rather than on the core structure (Gill et al. 2008). Majority of sensing techniques employing QDs in biological systems are applied in solution (colloidal form). Up to present days, the most frequently used approaches have been reported on the preparation of colloidal QDs: hydrophobic with subsequent solubilisation step, direct aqueous synthesis or two-phase synthesis. Compared with hydrophobic or two-phase approaches, aqueous synthesis is reagent-effective, less toxic and more reproducible. Furthermore, the products often show improved water-stability and biological compatibility. The current issue solved in the area of QDs synthesis is to find highly luminescent semiconducting nanocrystals, which are easy to prepare, biocompatible, stable and soluble in aqueous solutions. Thus, the semiconductor core material must be protected from degradation and oxidation to optimize QDs performance. Shell growth and surface modification enhance the stability and increase the photoluminescence of the core. 
The key step in QDs preparation ensuring the achievement of above mentioned required properties is based on QDs functionalization. Most of these approaches are based on bioconjugation with some biomolecule (Cai et al. 2007). Many biocompatible molecules can be used for this purpose; however glutathione (GSH) tripeptide possessing the surface amino and carboxyl functional groups gained special attention, since it is considered to be the most powerful, most versatile, and most important of the body's self-generated antioxidants. GSH coated QDS can be further modified, for example with biotin giving biotinylated-GSH QDs which can be employed in specific labelling strategies (Ryvolova et al. 2011). Namely, these biotin functionalized GSH coated QDs have high specific affinity to avidin (respectively streptavidin and neutravidin) (Chomoucka et al. 2010).

\section{Glutathione as promising QDs capping agent}

GSH is linear tripeptide synthesized in the body from 3 amino acids: L-glutamate, Lcysteine, and glycine (Y.F. Liu \& J.S. Yu 2009) (Fig. 1.). These functional groups provide the possibility of being coupled and further cross-linked to form a polymerized structure (Zheng et al. 2008). Thiol group of cysteine is very critical in detoxification and it is the active part of the molecule which serves as a reducing agent to prevent oxidation of tissues (J.P. Yuan et al. 2009). Besides its thiol group acting as capping agent, each GSH molecule also contains one amine and two carboxylate groups (Chomoucka et al. 2009).

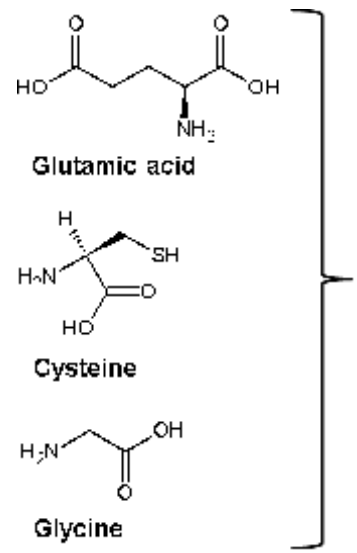<smiles>NC(CCC(=O)N[C@@H](CS)C(=O)NCC(=O)O)C(=O)O</smiles>

Glutathione (GSH; $\gamma$-L-Glutamy|-L-cysteineylglicine)

Fig. 1. Structure of glutathione

GSH is presented in almost all living cells, where it maintains the cellular redox potential. The liver, spleen, kidneys, pancreas, lens, cornea, erythrocytes, and leukocytes, have the highest concentrations in the body, ordinarily in the range from 0.1 to $10 \mathrm{mM}$. It belongs to powerful anti-viral agents and antioxidants for the protection of proteins, which neutralize free radicals and prevent their formation (Helmut 1999). Moreover, it is considered to be one of the strongest anti-cancer agents manufactured by the body. GSH's important role is also in the liver for detoxification of many toxins including formaldehyde, acetaminophen, benzpyrene and many other compounds and heavy metals such as mercury, lead, arsenic and especially cadmium, which will be discussed later concerning the toxicity level of Cdbased QDs. GSH is involved in nucleic acid synthesis and helps in DNA repairing (Milne et 
al. 1993). It slows the aging processes; however its concentration decreases with age. GSH must be in its reduced form to work properly. Reduced GSH is the smallest intracellular thiol (-SH) molecule. Its high electron-donating capacity (high negative redox potential) combined with high intracellular concentration (milimolar levels) generate great reducing power. This characteristic underlies its potent antioxidant action and enzyme cofactor properties, and supports a complex thiol-exchange system, which hierarchically regulates cell activity.

\section{Synthesis of hydrophobic QDs}

The synthesis of the most frequently used semiconducting colloidal QDs, consisted of metal chalcogenides (sulphides, selenides and tellurides), is based either on the usage of organometallic precursors (e.g. dimethylcadmium, diethylzinc), metallic oxide (e.g. CdO, $\mathrm{ZnO}$ ) or metallic salts of inorganic and organic acids (e.g. zinc stearate, cadmium acetate, cadmium nitrate (Bae et al. 2009)). The sources of chalcogenide anion are usually pure chalcogen elements (e.g. S, Se, Te). Whatever precursor is used, the resulted QDs are hydrophobic, but their quantum yields (QY) are higher (in the range of 20-60\%) compared to the QDs prepared by aqueous synthesis route (below $30 \%$ ). However, the trend is to avoid the usage of organometallic precursors, because they are less environmentally benign compared to other ones, which are more preferable (Mekis et al. 2003).

The most common approach to the synthesis of the colloidal hydrophobic QDs is the controlled nucleation and growth of particles in a solution of organometallic/chalcogen precursors containing the metal and the anion sources. The method lies in rapid injection of a solution of chemical reagents into a hot and vigorously stirred coordinating organic solvent (typically trioctylphosphine oxide (TOPO) or trioctylphosphine (TOP)) that can coordinate with the surface of the precipitated QDs particles (Talapin et al. 2010). Consequently, a large number of nucleation centres are initially formed at about $300^{\circ} \mathrm{C}$. The coordinating ligands in the hot solvents prevent or limit subsequent crystal growth (aggregation) via Ostwald ripening process (small crystals, which are more soluble than the large ones, dissolve and reprecipitate onto larger particles), which typically occurs at temperatures in the range of 250-300 ${ }^{\circ} \mathrm{C}$ (Merkoci 2009). Further improvement of the resulting size distribution of the QDs particles can be achieved through selective preparation (Mićić \& Nozik 2002). Because these QDs are insoluble in aqueous solution and soluble in nonpolar solvents only, further functionalization is required to achieve their solubilization. However, this inconveniency is compensated with higher QY of these QDs as mentioned previously.

\subsection{Solubilization of hydrophobic QDs}

Solubilization of QDs is essential for many biological and biomedical applications and presents a significant challenge in this field. Transformation process is complicated and involves multiple steps. Different QDs solubilization strategies have been discovered over the past few years. Non-water soluble QDs can be grown easily in hydrophobic organic solvents, but the solubilization requires sophisticated surface chemistry alteration. Current methods for solubilization without affecting key properties are mostly based on exchange of the original hydrophobic surfactant layer (TOP/TOPO) capping the QDs with hydrophilic one or the addition of a second layer (Jamieson et al. 2007). However, in most cases, the surface exchange results in not only broadening of the size distribution but also 
in reductions of QY from $80 \%$ in the organic phase to about $40 \%$ in aqueous solution (Tian et al. 2009).

The first technique involves ligand exchange (sometimes called cap exchange). The native hydrophobic ligands are replaced by bifunctional ligands of surface anchoring thiolcontaining molecules (see Fig. 2.) (usually a thiol, e.g. sodium thioglycolate) or more sophisticated ones (based on e.g. carboxylic or amino groups) such as oligomeric phosphines, dendrons and peptides to bind to the QDs surface and hydrophilic end groups (e.g. hydroxyl and carboxyl) to render water solubility. The second strategy employs polymerized silica shells functionalized with polar groups using a silica precursor during the polycondensation to insulate the hydrophobic QDs. While nearly all carboxy-terminated ligands limit QDs dispersion to basic $\mathrm{pH}$, silica shell encapsulation provides stability over much broader $\mathrm{pH}$ range. The third method maintains native ligands on the QDs and uses variants of amphiphilic diblock and triblock copolymers and phospholipids to tightly interleave the alkylphosphine ligands through hydrophobic interactions (Michalet et al. 2005; Xing et al. 2009). Aside from rendering water solubility, these surface ligands play a critical role in insulating, passivating and protecting the QD surface from deterioration in biological media (Cai et al. 2007).
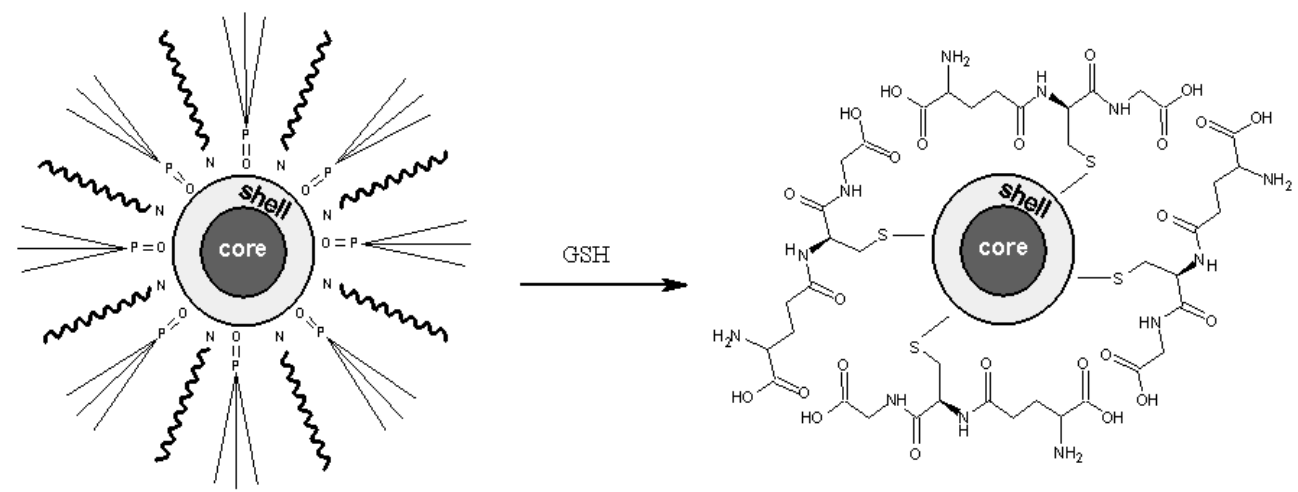

Fig. 2. Schematic representation of water soluble GSH-QDs preparation

An interesting work dealing with synthesis of hydrophobic QDs using chalcogen and metal oxide precursors and their following solubilisation with GSH was recently published by Jin et al. (Jin et al. 2008). The authors prepared highly fluorescent, water-soluble GSH-coated CdSeTe/CdS QDs emitting in near-infrared region (maximum emission at $800 \mathrm{~nm}$ ) and tested them as optical contrast agents for in vivo fluorescence imaging. NIR emitting QDs are very suitable for in vivo imaging mainly due to low scattering and the absorption of NIR light in tissues. The preparation is based on surface modification of hydrophobic CdSeTe/CdS (core/shell) QDs with GSH in tetrahydrofuran-water solution. GSH is added in relatively high concentration of $30 \mathrm{mg}$ for $1 \mathrm{ml}$ of solution and its excess is finally removed by dialysis. The resulting GSH-QDs were stocked in PBS $(\mathrm{pH}=7.4)$ and exhibited the QY of $22 \%$.

Similarly, highly luminescent CdSe/ZnS QDs were synthesized by Gill and colleagues, who used GSH-capped QDs, which were further functionalized with fluorescein 
isothiocyanate-modified avidin (Gill et al. 2008). The resulting avidin-capped QDs were used in all ratiometric analyses of $\mathrm{H}_{2} \mathrm{O}_{2}$ and their fluorescence QY was about $20 \%$.

Tortiglione et al. prepared GSH-capped CdSe/ZnS QDs in three steps (Tortiglione et al. 2007). At first, they synthesized TOP/TOPO-capped CdSe/ZnS core/shell QDs via the pyrolysis of precursors, trioctylphosphine selenide and organometallic dimethylcadmium, in a coordinating solvent. Diethylzinc and hexamethyldisilathiane were used as Zn and S precursors, respectively in the formation of ZnS shell around CdSe core. Due to their hydrophobic properties, CdSe/ZnS QDs were subsequently transferred into aqueous solution by standard procedure of wrapping up them in an amphiphilic polymer shell (diamino-PEG 897). Finally, the PEG-QDs were modified with GSH via formation of an amide bond with free amino groups of the diamino-PEG. These functionalized fluorescent probes can be used for staining fresh water invertebrates (e.g. Hydra vulgaris).. GSH is known to promote Hydra feeding response by inducing mouth opening.

\section{Aqueous synthesis of GSH coated QDs}

The second and more utilized way is the aqueous synthesis, producing QDs with excellent water solubility, biological compatibility, and stability (usually more than two months). Compared with organic phase synthesis, aqueous synthesis exhibits good reproducibility, low toxicity, and it is inexpensive. Basically, the fabrication process of water-soluble QDs takes place in reflux condenser (usually in a three-necked flask equipped with this reflux condenser). Nevertheless, this procedure in water phase needs a very long reaction time ranging from several hours to several days. Recently, new strategies employing microwaveassisted (MW) synthesis, which seems to be faster compared to the reflux one, were published as well (see below).

The other disadvantages of QDs synthesized through aqueous route are the wider FWHM (the full width at half maximum) and lower QY which can attribute to defects and traps on the surface of nanocrystals (Y.-F. Liu \& J.-S. Yu 2009). These defects can be eliminated by the selection of capping agents. The process of functionalization involves ligand exchange with thioalkyl acids such as thioglycolic acid (TGA) (Xu et al. 2008), mercaptoacetic acid (MAA) (Abd El-sadek et al. 2011), mercaptopropionic acid (MPA) (Cui et al. 2007), mercaptoundecanoic acid (MUA) (Aldeek et al. 2008), mercaptosuccinic acid (MSA) (Huang et al. 2007) or reduced GSH.

From these ligands, GSH seems to be a very perspective molecule, since it provides an additional functionality to the QDs due to its key function in detoxification of heavy metals (cadmium, lead) in organism (Ali et al. 2007).

GSH is not only an important water-phase antioxidant and essential cofactor for antioxidant enzymes, but it also plays roles in catalysis, metabolism, signal transduction, and gene expression. Thus, GSH QDs as biological probe should be more biocompatible than other thiol-capping ligands. Concerning the application, GSH QDs can be used for easy determination of heavy metals regarding the fact, that the fluorescence is considerably quenched at the presence of heavy metals. Similarly, GSH QDs exhibit high sensitivity to $\mathrm{H}_{2} \mathrm{O}_{2}$ produced from the glucose oxidase catalysing oxidation of glucose and therefore glucose can 
be sensitively detected by the quenching of the GSH QDs florescence (Saran et al. 2011; J. Yuan et al. 2009).

\subsection{QDs synthesis in reflux condenser}

This synthesis route usually consists in reaction of heavy metal $(\mathrm{Zn}, \mathrm{Cd}, \ldots)$ precursor with chalcogen precursors. Ordinarily used precursors of heavy metals easily dissolving in water are acetates, nitrates or chlorides. The chalcogen precursors can be either commercial solid powders (e.g. $\mathrm{Na}_{2} \mathrm{TeO}_{3}$ in the case of $\mathrm{CdTe} Q \mathrm{QDs}$ ) or freshly prepared before using in reaction procedure, e.g. $\mathrm{H}_{2} \mathrm{Te}$ (preparation by adding sulphuric acid dropwise to the aluminium telluride $\left(\mathrm{Al}_{2} \mathrm{Te}_{3}\right)$ (Zheng et al. 2007a)) or NaHTe (forming by reaction of sodium borohydride $\left(\mathrm{NaBH}_{4}\right)$ with Te powder (He et al. 2006; Zhang et al. 2003)) in the case of CdTe QDs. However, NaHTe and $\mathrm{H}_{2} \mathrm{Te}$ are unstable compounds under ambient conditions; therefore the synthesis of CdTe QDs generally has to be performed in inert reaction systems (see Fig. 3.). Since $\mathrm{Na}_{2} \mathrm{TeO}_{3}$ is air-stable, all of operations can be performed in the air, avoiding the need for an inert atmosphere. The synthetic pathway is thus free of complicated vacuum manipulations and environmentally friendly.

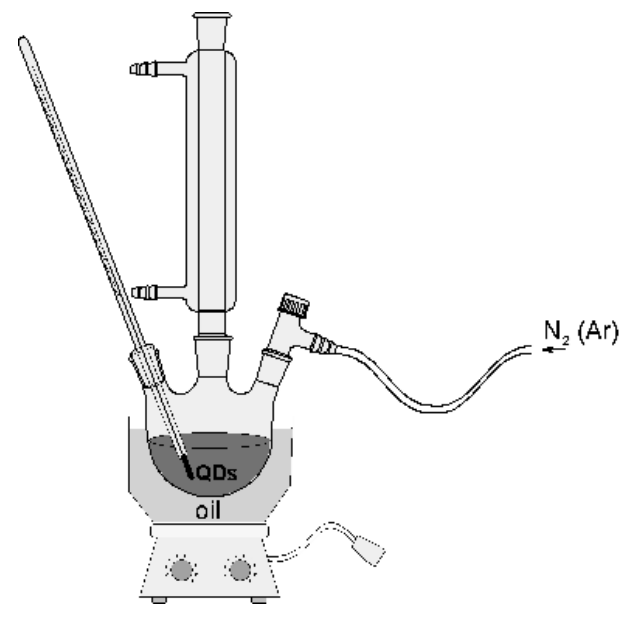

Fig. 3. Schema of apparatus for water soluble QDs preparation in reflux condenser

\subsubsection{CdTe QDs capped with GSH}

Xue et al. synthesized GSH-capped CdTe QDs by mixing the solutions of cadmium acetate and GSH and following injection of NaHTe solution under argon atmosphere and heating (Xue et al. 2011). After refluxing, QDs were precipitated with an equivalent amount of 2propanol, followed by resuspension in a minimal amount of ultrapure water. Excess salts were removed by repeating this procedure three times, and the purified QDs were dried overnight at room temperature in vacuum. These GSH-QDs showed excellent photostability and possessed high QY (42\%) without any post-treatment. The authors conjugated the QDs with folic acid and studied how these labelled QDs can specifically target folic acid receptor on the surface of human hepatoma and human ovarian cancer cell to demonstrate their potentially application as biolabels. 
Another GSH-functionalized QDS, namely CdTe and CdZnSe, were prepared by Ali et al. (Ali et al. 2007). The first mentioned were synthesized from $\mathrm{H}_{2} \mathrm{Te}$ and $\mathrm{CdCl}_{2}$, while in the second case NaHSe, $\mathrm{ZnCl}_{2}, \mathrm{H}_{2} \mathrm{Se}$ were used. Both types of GSH-capped QDs were coupled with a highthroughput detection system, to provide quick and ultrasensitive $\mathrm{Pb}^{2+}$ detection without the need of additional electronic devices. The mechanism is based on selective reduction of GSH-capped QDs in the presence of $\mathrm{Pb}^{2+}$ which results in fluorescence quenching that can be attributed to the stronger binding between heavy metal ions and the surface of GSH capping layer.

Also Goncalves and colleagues employed the simple experimental procedure for GSHcapped CdTe QDs fabrication and investigated the fluorescence intensity quenching in the presence of $\mathrm{Pb}^{2+}$ ions (Goncalves et al. 2009). Briefly, they mixed $\mathrm{CdCl}_{2}$ and $\mathrm{GSH}$ aqueous solutions with freshly prepared NaHTe solution and the mixture was refluxed up to $8 \mathrm{~h}$.

The same reactants for the synthesis of GSH-capped CdTe QDs were used by Cao M. et al. (Cao et al. 2009) and Dong et al. (Dong et al. 2010a). Cao and co-authors studied QDs interactions (fluorescence quenching) with heme-containing proteins and they found their optical fluorescence probes can be used for the selective determination of cytochrome $c$ under optimal $\mathrm{pH}$ value. While Dong et al. used their GSH-CdTe QDs as fluorescent labels to link bovine serum albumin (BSA) and rat anti-mouse CD4, which was expressed on mouse T-lymphocyte and mouse spleen tissue. The authors demonstrated that CdTe QDsbased probe exhibited much better photostability and fluorescence intensity than one of the most common fluorophores, fluorescein isothiocyanate (FITC), showing a good application potential in the immuno-labeling of cells and tissues.

Wang and colleagues reported on the preparation of three kinds of water-soluble QDs, MAAcapped CdTe QDs, MAA-capped CdTe/ZnS and GSH-capped CdTe QDs, and compared the change of their fluorescence intensity (quenching) in the presence of As (III)(Wang et al. 2011). Arsenic (III) has a high affinity to reduced GSH to form As(SG) $)_{3}$ thus the fluorescence of GSH coated QDs is reduced significantly in the presence of As (III). MAA-capped CdTe QDs were prepared through reaction of $\mathrm{CdCl}_{2}$ and MAA with subsequent injection of freshly prepared NaHTe solution under vigorous magnetic stirring. Then the precursor solution was heated and refluxed under $\mathrm{N}_{2}$ protection for $60 \mathrm{~min}$. Finally, cold ethanol was added and MAA-CdTe QDs were precipitated out by centrifugation. A similar procedure was used for GSH-capped CdTe QDs synthesis with only one difference: the precipitation process was repeated for three times in order to eliminate free GSH ligands and salts in the GSH-CdTe QDs colloids. MAA-capped CdTe/ZnS QDs were prepared also similarly. When the CdTe precursor was refluxed for $30 \mathrm{~min}, \mathrm{ZnCl}_{2}$ and $\mathrm{Na}_{2} \mathrm{~S}$ were added slowly and simultaneously to form $\mathrm{ZnS}$ shell. After $30 \mathrm{~min}$, the products were separated by the addition of cold ethanol and centrifugation.

Different thiol ligands, including TGA, L-cysteine (L-Cys) and GSH for capping CdTe QDs were also tested by Li Z. et al. (Z. Li et al. 2010). The starting materials were identical as in previous mentioned studies, i.e. NaHTe and $\mathrm{CdCl}_{2}$. The luminescent properties of CdTe QDs with different stabilizing agents were studied by using fluorescence spectra, which showed that CdTe QDs with longer emission wavelength $(680 \mathrm{~nm})$ can be synthesized more easily when L-Cys or GSH is chosen as stabilizing agents. Moreover, the authors found that the cytotoxicity of TGA-QDs is higher than that of L-Cys- and GSH-CdTe. Ma et al. also prepared CdTe QDs modified with these three thiol-complex, namely TGA, L-cys and GSH and investigated the interactions of prepared QDs with BSA using spectroscopic methods (UV-VIS, IR and fluorescence spectrometry) (Ma et al. 2010). 
Tian et al. (Tian et al. 2009) used for the first time GSH and TGA together to enhance stability of water soluble CdTe QDs prepared using $\mathrm{NaHTe}$ and $\mathrm{CdCl}_{2}$. The author prepared different-sized CdTe QDs with controllable photoluminescence wavelengths from 500 to 610 $\mathrm{nm}$ within $5 \mathrm{~h}$ at temperature of $100^{\circ} \mathrm{C}$. When the molar ratio of GSH to TGA is 1:1, QY of the yellow-emitting CdTe (emission maximum at $550 \mathrm{~nm}$ ) reached $63 \%$ without any posttreatment. The synthesized CdTe QDs possess free carboxyl and amino groups, which were successfully conjugated with insulin for delivery to cells, demonstrating that they can be easily bound bimolecularly and have potentially broad applications as bioprobes.

Yuan et al. replaced NaHTe with more convenient $\mathrm{Na}_{2} \mathrm{TeO}_{3}$ for preparation of CdTe QDs, namely they used $\mathrm{CdCl}_{2}$ and $\mathrm{Na}_{2} \mathrm{TeO}_{3}$, which were subsequently mixed with MSA or GSH as capping agent (J. Yuan et al. 2009). The prepared QDs were tested for glucose detection by monitoring QDs photoluminescence quenching as consequence of $\mathrm{H}_{2} \mathrm{O}_{2}$ presence and acidic changes produced by glucose oxidase catalysing glucose oxidation, respectively. The authors found that the sensitivity of QDs to $\mathrm{H}_{2} \mathrm{O}_{2}$ depends on QDs size: smaller size presented higher sensitivity. The quenching effect of $\mathrm{H}_{2} \mathrm{O}_{2}$ on GSH-capped QDs was more than two times more intensive than that on MSA-capped QDs.

\subsubsection{CdSe QDs capped with GSH}

Compared to CdTe QDs, GSH-capped CdSe QDs are much readily prepared. Jing et al. synthesized TGA-capped CdSe QDs using $\mathrm{CdCl}_{2}$ and $\mathrm{Na}_{2} \mathrm{SeO}_{3}$, and they used these QDs for hydroxyl radical electrochemiluminescence sensing of the scavengers (Jiang \& Ju 2007).

The research group of Dong, mentioned in synthesis of CdTe QDs, also prepared two kinds of highly fluorescent GSH-capped CdSe/CdS core-shell QDs emitting green and orange fluorescence at $350 \mathrm{~nm}$ excitation by an aqueous approach (Dong et al. 2010b). The authors used these QDs as fluorescent labels to link mouse anti-human CD3 which was expressed on human T-lymphocyte. Compared to CdSe QDs, they found a remarkable enhancement in the emission intensity and a red shift of emission wavelength for both types of core-shell CdSe/CdS QDs. They demonstrated that the fluorescent CdSe/CdS QDs exhibited much better photostability and brighter fluorescence than FITC.

\subsubsection{CdS QDs capped with GSH}

Also thiol-capped CdS QDs are less studied in comparison with CdTe QDs. MPA belongs to the most tested thiol ligands for capping these QDS (Huang et al. 2008). Liang et al. synthesized GSH-capped CdS QDs in aqueous solutions from $\mathrm{CdCl}_{2}$ and $\mathrm{CH}_{3} \mathrm{CSNH}_{2}$ (thioacetamide) at room temperature (Liang et al. 2010). In this synthesis procedure, GSH was added in the final step into previously prepared CdS QDs solution. The obtained GSH coated QDs were tested as fluorescence probes to determine of $\mathrm{Hg}^{2+}$ with high sensitivity and selectivity. Under optimal conditions, the quenched fluorescence intensity increased linearly with the concentration of $\mathrm{Hg}^{2+}$.

Merkoci et al. employed another preparation process: $\mathrm{GSH}$ and $\mathrm{CdCl}_{2}$ were first dissolved in water with subsequent addition of TMAH (tetramethylammoniumhydroxide) and ethanol. After degassing, HMDST (hexamethyldisilathiane) was quickly added as sulphide precursor, giving a clear (slightly yellow) colloidal solution of water soluble CdS QDs modified with GSH (Merkoci et al. 2007). The authors used these QDs as a model compound 
in a direct electrochemical detection of CdS QDs or other similar QDs, based on the squarewave voltammetry of CdS QDs suspension dropped onto the surface of a screen printed electrode. This detection method is simple and low cost compared to optical methods and it will be interesting for bioanalytical assays, where CdS QDs can be used as electrochemical tracers, mainly in fast screening as well as in field analysis.

Thangadurai and colleagues investigated 5 organic thiols as suitable capping agent for CdS QDs (diameter of 2-3.3 nm), namely 1,4-dithiothreitol (DTT), 2-mercaptoethanol , L-Cys, methionine and GSH (Thangadurai et al. 2008). The QDs were prepared by a wet chemical method from $\mathrm{Cd}\left(\mathrm{NO}_{3}\right)_{2}$ and $\mathrm{Na}_{2} \mathrm{~S}$. Briefly, the process started with addition of capping agent aqueous solution to the solution of $\mathrm{Cd}\left(\mathrm{NO}_{3}\right)_{2}$ and stirred for $12 \mathrm{~h}$ at room temperature and under dry $\mathrm{N}_{2}$ atmosphere. In the second step, $\mathrm{Na}_{2} \mathrm{~S}$ solution was added dropwise and stirred for another $12 \mathrm{~h}$. The CdS prepared with and without coating appeared greenish yellow and dark orange, respectively. The authors revealed the CdS QDs being in cubic phase. According to FT-IR studies, they suggested two different bonding mechanisms of the capping agents with the CdS. DTT was found to be the best capping agent for CdS from all tested thiols because of lower grain size in cubic phase and good fluorescence properties with efficient quenching of the surface traps.

Jiang et al. prepared GSH-capped aqueous CdS QDs with strong photoluminescence (QY of $36 \%$ ) using $\mathrm{CdCl}_{2}$ and $\mathrm{Na}_{2} \mathrm{~S}$ by typical procedure (Jiang et al. 2007). The excitation spectrum was broad ranging from 200 to $480 \mathrm{~nm}$. These QDs were conjugated with BSA and tested as fluorescence probes. The results demonstrated that the fluorescence of CdS QDs can be enhanced by BSA depending on BSA concentration.

\subsubsection{Zn-based QDs capped with GSH}

Generally, the QDs fluorescent colour can be tuned by changing their size which depends mainly on reaction time. There is also another option how to tune the colour of QDs emission without changing the QDs size using alloyed QDs, which is the most frequently used approach for Zn-based QDs. Alloyed QDs are traditionally fabricated in two step synthesis route, for example by incorporation of $\mathrm{Cd}^{2+}$ into very small $\mathrm{ZnSe}$ seeds (Zheng et al. 2007b). Subsequent stabilization of these QDs is usually ensured with thiol compounds. Cao et al. prepared water-soluble violet-green emitting core/shell $\mathrm{Zn}_{1-x} \mathrm{Cd}_{\mathrm{x}} \mathrm{Se} / \mathrm{ZnS}$ QDs using N-acetyl-1-cysteine (NAC) as a stabilizer (Cao et al. 2010). ZnS shell provided reduction of $\mathrm{Zn}_{1-x} \mathrm{Cd}_{\mathrm{x}} \mathrm{Se}$ core cytotoxicity and increase of QY up to $30 \%$, while NAC resulted in excellent biocompatibility of these QDs.

Liu and colleagues synthesized alloyed $\mathrm{Zn}_{x} \mathrm{Hg}_{1-x} \mathrm{Se}$ QDs capped with GSH in one step process by reacting a mixture of $\mathrm{Zn}\left(\mathrm{ClO}_{4}\right)_{2}, \mathrm{Hg}\left(\mathrm{ClO}_{4}\right)_{2}$ and $\mathrm{GSH}$ with freshly prepared NaHSe (Liu et al. 2009). The fluorescent color of the alloyed QDs can be easily tuned in the range of $548-621 \mathrm{~nm}$ by varying the $\mathrm{Zn}^{2+}: \mathrm{Hg}^{2+}$ molar ratio, reaction $\mathrm{pH}$, intrinsic $\mathrm{Zn}^{2+}$ and $\mathrm{Hg}^{2+}$ reactivity toward NaHSe, and the concentration of NaHSe. These GSH-capped $\mathrm{Zn}_{0.96} \mathrm{Hg}_{0.04} \mathrm{Se}$ QDs possessed high QY (78 \%) and were applied for sensing $\mathrm{Cu}^{2+}$. Ying et al. synthesized another type of alloyed QDs, namely GSH-capped $\mathrm{Zn}_{1-\mathrm{x}} \mathrm{Cd}_{\mathrm{x}} \mathrm{Se}$ QDs with tunable fluorescence emissions (360-700 nm) and QY up to $50 \%$ (Ying et al. 2008). Lesnyak and colleagues demonstrated a facile one-step aqueous synthesis of blue-emitting GSH-capped $\mathrm{ZnSe}_{1-\mathrm{x}} \mathrm{Te}_{\mathrm{x}}$ QDs with QY up to $20 \%$ (Lesnyak et al. 2010). Li et al. prepared GSH-capped 
alloyed $\mathrm{Cd}_{\mathrm{x}} \mathrm{Zn}_{1-\mathrm{x}} \mathrm{Te}$ QDs through a one-step aqueous route (W.W. Li et al. 2010). These QDs with high QY up to $75 \%$ possessed broadened band gap, hardened lattice structure and lower defect densities. Their emission wavelength can be tuned from 470 to $610 \mathrm{~nm}$. The authors suggested the usage of such QDs as promising optical probes in bio-applications or in detection of heavy metal ions (e.g. $\mathrm{Pb}^{2+}, \mathrm{Hg}^{2+}$ ).

Deng et al. examined two other thiol ligands beside GSH, MPA and TGA, for stabilization of $\mathrm{ZnSe}$ and $\mathrm{Zn}_{\mathrm{x}} \mathrm{Cd}_{1-\mathrm{x}} \mathrm{Se}$ QDs synthesized by water-based route (Deng et al. 2009). A typical synthetic procedure for ZnSe QDs started with mixing $\mathrm{Zn}\left(\mathrm{NO}_{3}\right)_{2}$, thiol molecule and $\mathrm{N}_{2} \mathrm{H}_{4}$ (hydrazine), which was used to maintain oxygen-free conditions, allowing the reaction vessel to be open to air. In the next step, freshly prepared NaHSe solution was added to the flask with vigorous stirring and the $\mathrm{pH}$ was adjusted to 11 using $1 \mathrm{M} \mathrm{NaOH}$. The mixture was refluxed at temperature close to $100{ }^{\circ} \mathrm{C}$ which resulted in light blue solution as ZnSe QDs grew. The prepared QDs possessed tunable and narrow photoluminescence (PL) peaks ranging from 350 to $490 \mathrm{~nm}$. The authors found that MPA capping agent gave rise to smaller ZnSe QDs with a high density of surface defects, while TGA and GSH produced larger ZnSe QDs with lower surface defect densities. According to absorption spectra, the growth was more uniform and better controlled with linear two-carbon TGA (QDs size of $2.5 \mathrm{~nm}$ ) than with GSH, which is branched bifunctional molecule. Concerning $\mathrm{Zn}_{x} \mathrm{Cd}_{1-x} \mathrm{Se}$ QDs, the preparation was performed in a reducing atmosphere by addition of Cd-thiol complex directly to ZnSe QDs solution. The PL peaks changed from 400 to $490 \mathrm{~nm}$ by changing the $\mathrm{Zn}$ to $\mathrm{Cd}$ ratio.

Fang et al. fabricated water-dispersible GSH-capped ZnSe/ZnS core/shell QDs with high QY up to $65 \%$ (Fang et al. 2009). In the first step, GSH-capped ZnSe core was synthesized by mixing zinc acetate with GSH solution. The $\mathrm{pH}$ of solution was adjusted to 11.5 by addition of $2 \mathrm{M} \mathrm{NaOH}$. Subsequently, fresh NaHSe solution was added at room temperature. The system was heated to $90{ }^{\circ} \mathrm{C}$ under $\mathrm{N}_{2}$ atmosphere for $1 \mathrm{~h}$ which resulted in formation of ZnSe core with an average size of $2.7 \mathrm{~nm}$. In the second step, ZnS shell was created in reaction of as-prepared ZnSe core with shell precursor compounds (zinc acetate as zinc resource and thiourea as sulphur resource) at $90^{\circ} \mathrm{C}$. In comparison to the plain ZnSe QDs, both the QY and the stability against UV irradiation and chemical oxidation of $\mathrm{ZnSe} / \mathrm{ZnS}$ core/shell QDs have been greatly improved.

\subsection{Microwave irradiation synthesis}

As mentioned above, long reaction times in aqueous phase often result in a large number of surface defects on synthesized QDs with low photoluminescence QY. Hydrothermal and microwave (MW) irradiation methods can replace traditional reflux methods and provide high-quality QDs in shorter time (Zhu et al. 2002). Especially, MW synthesis is advantageous due to rapid homogeneous heating realized through the penetration of microwaves. Compared to conventional thermal treatment, this way of heating allows the elimination of defects on QDs surface and produces uniform products with higher QY (Duan et al. 2009). The sizes of QDs can be easily tuned by varying the heating times. The QDs growth stops when the MW irradiation system is off and product is cooled down.

From chemical point of view, the most frequent types of QDs synthesized using microwave irradiation are $\mathrm{CdTe}, \mathrm{CdSe}, \mathrm{CdS}, \mathrm{Zn}_{1-\mathrm{x}} \mathrm{Cd}_{\mathrm{x}} \mathrm{Se}$ and $\mathrm{ZnSe}$. As usual, these QDs can be 
functionalized with various thiol ligands such as MPA, MSA (Kanwal et al. 2010), TGA, 1butanethiol, 2-mercaptoethanol (Majumder et al. 2010) or GSH (Qian et al. 2006). However, thiol ligands can be also used as sulphur source in one-step MW synthesis of QDs. Qian et al. reported on a seed-mediated and rapid synthesis of CdSe/CdS QDs using MPA, which was decomposed during MW irradiation releasing S2- anions at temperature of $100{ }^{\circ} \mathrm{C}$ (Qian et al. 2005). In this step, only CdSe monomers were nucleated and grown by the reaction of NaHSe and cadmium chloride. The initial core was rich in Se due to the faster reaction of Se with $\mathrm{Cd}^{2+}$ compared to $\mathrm{S}$. The amount of released $\mathrm{S}^{2-}$ anions increased, when the temperature rose to $140{ }^{\circ} \mathrm{C}$ which resulted in formation of alloyed CdSeS shell on the surface of CdSe nanocrystals. The resulted QDs showed the quantum yield up to $25 \%$.

Traditionally, GSH was used as thiol-capping agent for CdTe QDs in the work of other research group (Qian et al. 2006). Highly luminescent, water-soluble, and biocompatible CdTe QDs were synthesized in one-pot through reaction of $\mathrm{Cd}^{2+}-\mathrm{GSH}$ complex (using cadmium chloride as Cd source) with freshly prepared NaHTe in a sealed vessel under MW irradiation at $130{ }^{\circ} \mathrm{C}$ in less than $30 \mathrm{~min}$. The prepared nanocrystals possessed excellent optical properties and QY above $60 \%$. It is worth to note, that CdTe nanocrystals were tightly capped by $\mathrm{Cd}^{2+}-\mathrm{GSH}$ at a lower $\mathrm{pH}$ value (compared to other thiol ligands, e.g $\mathrm{pH}$ 11.2 in the case of MSA (Kanwal et al. 2010)), which inhibited the growth of the nanocrystals. With the decrease of $\mathrm{pH}$ value, the growth rate slows dramatically.

A similar approach for one-step synthesis of GSH-capped ZnSe QDs in aqueous media was employed in the work of Huang et al. (Huang \& Han 2010). The process was based on the reaction of air-stable $\mathrm{Na}_{2} \mathrm{SeO}_{3}$ with aqueous solution consisted of zinc nitrate and GSH. Then $\mathrm{NaBH}_{4}$ as reduction agent was added into the above mentioned solution with stirring. The $\mathrm{pH}$ was set to value of 10 by the addition of $\mathrm{NaOH}$. The mixture was then refluxed at $100{ }^{\circ} \mathrm{C}$ for $60 \mathrm{~min}$ under MW irradiation $(300 \mathrm{~W})$. The obtained QDs $(2-3 \mathrm{~nm})$, performed strong band-edge luminescence (QY reached 18\%).

\subsection{Microemulsion synthesis}

This fabrication route is widely used for QDs coated with thiol ligands, however, according to our best knowledge, only one publication deals with GSH as coating material. Saran and colleagues employed this technique for fabrication of various core-shell QDs, namely CdSe/CdS, CdSe/ZnS and CdS/ZnS) (Saran et al. 2011). Following, the authors tested three ligands: mercaptoacetic acid, mercaptopropionic acid and GSH to find the optimal capping agent for glucose monitoring (biosensing) in human blood, which is essential for diagnosis of diabetes. These optical biosensors, based on QDs conjugated with glucose oxidase using carbodiimide bioconjugation method, work on the phenomenon of fluorescence quenching with simultaneous release of $\mathrm{H}_{2} \mathrm{O}_{2}$, which is detected then.

The microemulsion synthesis method is a simple, inexpensive and highly reproducible method, which enables excellent control of nanoparticles size and shape (Saran \& Bellare 2010). This control of particle size is achieved simply by varying water-to-surfactant molar ratio. Nevertheless, the microemulsion synthesis gives relatively low yield of product; even large amounts of surfactant and organic solvent are used compared to bulk aqueous precipitation. The key point of this procedure is extraction of the nanoparticles from microemulsion into aqueous phase and to maintain their structural and surface features. In 
order to reach feasible yields of nanoparticles, the higher concentration of precursors in microemulsion should be used, which leads to much larger particle density inside the reverse micelles.

Briefly, a typical microemulsion synthesis of CdSe QDs can be described as follows: Se powder is added to $\mathrm{Na}_{2} \mathrm{SO}_{3}$ solution under continuous nitrogen bubbling at higher temperature forming $\mathrm{Na}_{2} \mathrm{SeSO}_{3}$ (sodium selenosulfate). Subsequently, this precursor was mixed with reverse micelle system prepared by dissolving AOT (sodium bis (2-ethylhexyl) sulfosuccinate) in n-heptane. A similar microemulsion was prepared with $\mathrm{Cd}\left(\mathrm{NO}_{3}\right)_{2}$. Finally, these two microemulsions were vortex-mixed which leaded to formation of CdSe QDs inside the reverse micelles. In the second step, a shell of CdS was created by the addition of $\left(\mathrm{NH}_{4}\right)_{2} \mathrm{~S}$ microemulsion under vortex-stirring. The last step consisted in core-shell QDs stabilization using thiol ligands aqueous solution, which is added to the solution of QDs. The process is accompanied with colour change of organic phase (initially orange-red) to translucent. This colour change indicated the complete transfer of thiol-capped QDs into the aqueous phase (Fig. 4.).

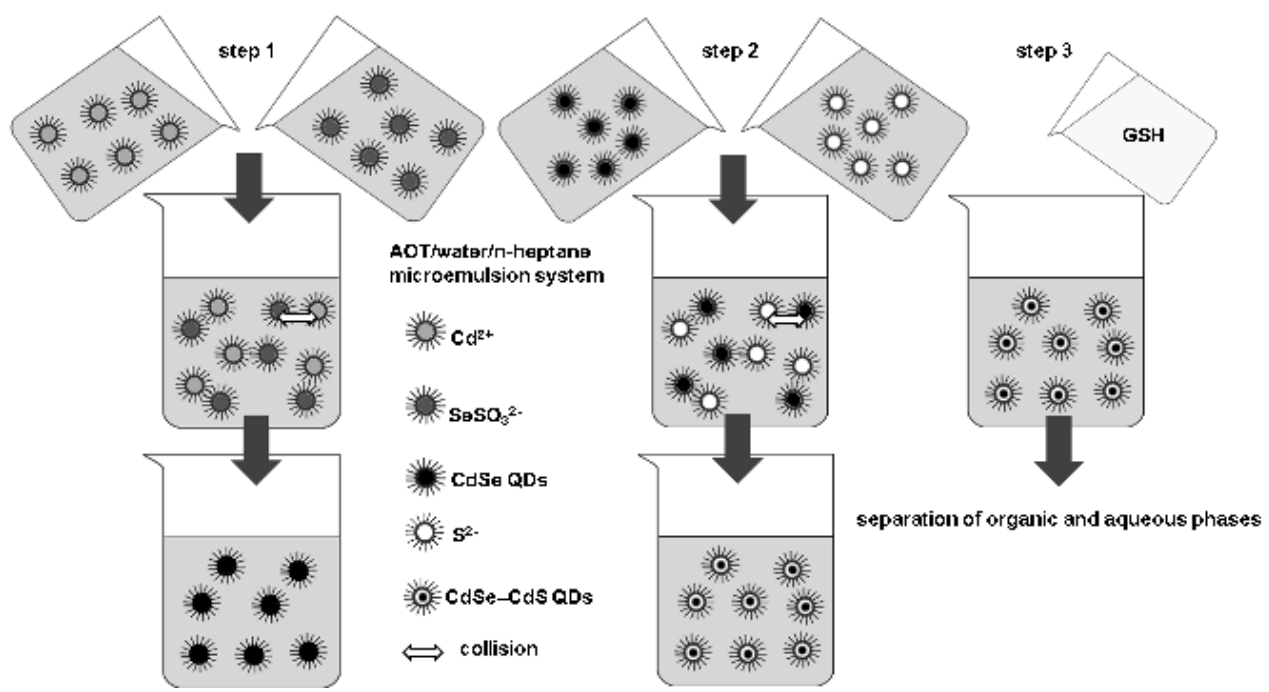

Fig. 4. Surface functionalization, recovery and stabilization of QDs from microemulsion into aqueous phase

\section{Conclusion}

Current issues solved in synthesis of highly luminescent QDs are their easy preparation, biocompatibility, stability and solubility in water. Up to now, the most frequently used approaches reported on the preparation of colloidal QDs are (1) synthesis of hydrophobic QDs with subsequent solubilization step, (2) direct aqueous synthesis or (3) two-phase synthesis. Compared with hydrophobic or two-phase approaches, aqueous synthesis is reagent-effective, less toxic and more reproducible. There is a variety of capping ligands used to provide solubility and biocompatibility of QDs in aqueous synthesis, mainly thiol organic compounds. Among them, GSH has gained the most attention due to its excellent 
properties and application in detection or sensing purposes. Our chapter describes the most commonly used techniques for preparation of various GSH-coated QDs based on heavy metal chalcogenides, namely CdTe, CdS, CdSe and alloyed or simple Zn-based QDs.

\section{Acknowledgement}

This work has been supported by Grant Agency of the Academy of Sciencies of the Czech Republic under the contract GAAV KAN208130801 (NANOSEMED) by Grant Agency of the Czech Republic under the contract GACR 102/10/P618 and by project CEITEC CZ.1.05/1.1.00/02.0068.

\section{References}

Abd El-sadek M.S.; Nooralden A.Y.; Babu S.M. \& Palanisamy P.K. (2011). Influence of different stabilizers on the optical and nonlinear optical properties of CdTe nanoparticles. Optics Communications, Vol. 284, No. 12, pp. 2900-2904, ISS N 00304018

Aldeek F.; Balan L.; Lambert J. \& Schneider R. (2008). The influence of capping thioalkyl acid on the growth and photoluminescence efficiency of CdTe and CdSe quantum dots. Nanotechnology, Vol. 19, No. 47, pp. ISS N 0957-4484

Ali E.M.; Zheng Y.G.; Yu H.H. \& Ying J.Y. (2007). Ultrasensitive Pb2+ detection by glutathione-capped quantum dots. Analytical Chemistry, Vol. 79, No. 24, pp. $9452-$ 9458, ISS N 0003-2700

Bae P.K.; Kim K.N.; Lee S.J.; Chang H.J.; Lee C.K. \& Park J.K. (2009). The modification of quantum dot probes used for the targeted imaging of his-tagged fusion proteins. Biomaterials, Vol. 30, No. 5, pp. 836-842, ISS N 0142-9612

Byers R.J. \& Hitchman E.R. (2011). Quantum Dots Brighten Biological Imaging. Progress in Histochemistry and Cytochemistry, Vol. 45, No. 4, pp. 201-237, ISS N 0079-6336

Cai W.B.; Hsu A.R.; Li Z.B. \& Chen X.Y. (2007). Are quantum dots ready for in vivo imaging in human subjects? Nanoscale Research Letters, Vol. 2, No. 6, pp. 265-281, ISS N 19317573

Cao J.; Xue B.; Li H.; Deng D. \& Gu Y. (2010). Facile synthesis of high-quality water-soluble $\mathrm{N}$-acetyl-1-cysteine-capped Zn1-xCdxSe/ZnS core/shell quantum dots emitting in the violet-green spectral range. Journal of Colloid and Interface Science, Vol. 348, No. 2, pp. 369-376, ISS N 0021-9797

Cao M.; Cao C.; Liu M.G.; Wang P. \& Zhu C.Q. (2009). Selective fluorometry of cytochrome c using glutathione-capped CdTe quantum dots in weakly basic medium. Microchimica Acta, Vol. 165, No. 3-4, pp. 341-346, ISS N 0026-3672

Chomoucka J.; Drbohlavova J.; Adam V.; Kizek R.; Hubalek J. \& Ieee. (2009). Synthesis of Glutathione-coated Quantum Dots, Ieee, ISB N 978-1-4244-4260-7, New York

Chomoucka J.; Drbohlavova J.; Babula P.; Adam V.; Hubalek J.; Provaznik I. \& Kizek R. (2010). Cell Toxicity and Preparation of Streptavidin-Modified Iron Nanoparticles and Glutathione-Modified Cadmium-Based Quantum Dots, Proceedings of Eurosensor Xxiv Conference, ISB N 1877-7058, Linz, 2010 
Cui R.; Pan H.C.; Zhu J.J. \& Chen H.Y. (2007). Versatile immunosensor using CdTe quantum dots as electrochemical and fluorescent labels. Analytical Chemistry, Vol. 79, No. 22, pp. 8494-8501, ISS N 0003-2700

Deng Z.T.; Lie F.L.; Shen S.Y.; Ghosh I.; Mansuripur M. \& Muscat A.J. (2009). Water-Based Route to Ligand-Selective Synthesis of ZnSe and Cd-Doped ZnSe Quantum Dots with Tunable Ultraviolet A to Blue Photoluminescence. Langmuir, Vol. 25, No. 1, pp. 434-442, ISS N 0743-7463

Dong W.; Ge X.; Wang M. \& Xu S.K. (2010a). Labeling of BSA and imaging of mouse Tlymphocyte as well as mouse spleen tissue by L-glutathione capped CdTe quantum dots. Luminescence, Vol. 25, No. 1, pp. 55-60, ISS N 1522-7235

Dong W.; Ge X.; Wang X.Y. \& Xu S.K. (2010b). Preparation of GSH Capped CdSe/CdS CoreShell QDs and Labeling of Human T-Lymphocyte. Spectroscopy and Spectral Analysis, Vol. 30, No. 1, pp. 118-122, ISS N 1000-0593

Drummen G.P.C. (2010). Quantum Dots-From Synthesis to Applications in Biomedicine and Life Sciences. International Journal of Molecular Sciences, Vol. 11, No. 1, pp. 154-163, ISS N 1422-0067

Duan J.L.; Song L.X. \& Zhan J.H. (2009). One-Pot Synthesis of Highly Luminescent CdTe Quantum Dots by Microwave Irradiation Reduction and Their $\mathrm{Hg}(2+)$-Sensitive Properties. Nano Research, Vol. 2, No. 1, pp. 61-68, ISS N 1998-0124

Fang Z.; Li Y.; Zhang H.; Zhong X.H. \& Zhu L.Y. (2009). Facile Synthesis of Highly Luminescent UV-Blue-Emitting ZnSe/ZnS Core/Shell Nanocrystals in Aqueous Media. Journal of Physical Chemistry C, Vol. 113, No. 32, pp. 14145-14150, ISS N 1932-7447

Gill R.; Bahshi L.; Freeman R. \& Willner I. (2008). Optical detection of glucose and acetylcholine esterase inhibitors by $\mathrm{H} 2 \mathrm{O} 2$-sensitive $\mathrm{CdSe} / \mathrm{ZnS}$ quantum dots. Angewandte Chemie-International Edition, Vol. 47, No. 9, pp. 1676-1679, ISS N 14337851

Goncalves H.; Mendonca C. \& da Silva J. (2009). PARAFAC Analysis of the Quenching of EEM of Fluorescence of Glutathione Capped CdTe Quantum Dots by Pb(II). Journal of Fluorescence, Vol. 19, No. 1, pp. 141-149, ISS N 1053-0509

He Y.; Lu H.T.; Sai L.M.; Lai W.Y.; Fan Q.L.; Wang L.H. \& Huang W. (2006). Microwaveassisted growth and characterization of water-dispersed CdTe/CdS core-shell nanocrystals with high photoluminescence. Journal of Physical Chemistry B, Vol. 110, No. 27, pp. 13370-13374, ISS N 1520-6106

Helmut S. (1999). Glutathione and its role in cellular functions. Free Radical Biology and Medicine, Vol. 27, No. 9-10, pp. 916-921, ISS N 0891-5849

Huang C.-P.; Li Y.-K. \& Chen T.-M. (2007). A highly sensitive system for urea detection by using CdSe/ZnS core-shell quantum dots. Biosensors and Bioelectronics, Vol. 22, No. 8, pp. 1835-1838, ISS N 0956-5663

Huang C.B.; Wu C.L.; Lai J.P.; Li S.Y.; Zhen J.S. \& Zhao Y.B. (2008). CdS quantum dots as fluorescence probes for the detection of selenite. Analytical Letters, Vol. 41, No. 11, pp. 2117-2132, ISS N 0003-2719 
Huang L. \& Han H.Y. (2010). One-step synthesis of water-soluble ZnSe quantum dots via microwave irradiation. Materials Letters, Vol. 64, No. 9, pp. 1099-1101, ISS N 0167$577 X$

Jamieson T.; Bakhshi R.; Petrova D.; Pocock R.; Imani M. \& Seifalian A.M. (2007). Biological applications of quantum dots. Biomaterials, Vol. 28, No. 31, pp. 4717-4732, ISS N 0142-9612

Jiang C.; Xu S.K.; Yang D.Z.; Zhang F.H. \& Wang W.X. (2007). Synthesis of glutathionecapped US quantum dots and preliminary studies on protein detection and cell fluorescence image. Luminescence, Vol. 22, No. 5, pp. 430-437, ISS N 1522-7235

Jiang H. \& Ju H.X. (2007). Electrochemiluminescence sensors for scavengers of hydroxyl radical based on its annihilation in CdSe quantum dots film/peroxide system. Analytical Chemistry, Vol. 79, No. 17, pp. 6690-6696, ISS N 0003-2700

Jin T.; Fujii F.; Komai Y.; Seki J.; Seiyama A. \& Yoshioka Y. (2008). Preparation and Characterization of Highly Fluorescent, Glutathione-coated Near Infrared Quantum Dots for in Vivo Fluorescence Imaging. International Journal of Molecular Sciences, Vol. 9, No. 10, pp. 2044-2061, ISS N 1422-0067

Kanwal S.; Traore Z.; Zhao C. \& Su X. (2010). Enhancement effect of CdTe quantum dotsIgG bioconjugates on chemiluminescence of luminol-H2O2 system. Journal of Luminescence, Vol. 130, No. 10, pp. 1901-1906, ISS N 0022-2313

Lesnyak V.; Dubavik A.; Plotnikov A.; Gaponik N. \& Eychmuller A. (2010). One-step aqueous synthesis of blue-emitting glutathione-capped $\mathrm{ZnSe}(1-\mathrm{x}) \mathrm{Te}(\mathrm{x})$ alloyed nanocrystals. Chemical Communications, Vol. 46, No. 6, pp. 886-888, ISS N 1359-7345

Li W.W.; Liu J.; Sun K.; Dou H.J. \& Tao K. (2010). Highly fluorescent water soluble $\mathrm{Cd}(\mathrm{x}) \mathrm{Zn}(1-\mathrm{x}) \mathrm{Te}$ alloyed quantum dots prepared in aqueous solution: one-step synthesis and the alloy effect of Zn. Journal of Materials Chemistry, Vol. 20, No. 11, pp. 2133-2138, ISS N 0959-9428

Li Z.; Wang Y.X.; Zhang G.X. \& Han Y.J. (2010). Luminescent Properties and Cytotoxicity of CdTe Quantum Dots with Different Stabilizing Agents. Journal of Inorganic Materials, Vol. 25, No. 5, pp. 495-499, ISS N 1000-324X

Liang A.N.; Wang L.; Chen H.Q.; Qian B.B.; Ling B. \& Fu J. (2010). Synchronous fluorescence determination of mercury ion with glutathione-capped CdS nanoparticles as a fluorescence probe. Talanta, Vol. 81, No. 1-2, pp. 438-443, ISS N 0039-9140

Liu F.-C.; Chen Y.-M.; Lin J.-H. \& Tseng W.-L. (2009). Synthesis of highly fluorescent glutathione-capped ZnxHg1-xSe quantum dot and its application for sensing copper ion. Journal of Colloid and Interface Science, Vol. 337, No. 2, pp. 414-419, ISS N 0021-9797

Liu Y.-F. \& Yu J.-S. (2009). Selective synthesis of CdTe and high luminescence CdTe/CdS quantum dots: The effect of ligands. Journal of Colloid and Interface Science, Vol. 333, No. 2, pp. 690-698, ISS N 0021-9797

Liu Y.F. \& Yu J.S. (2009). Selective synthesis of CdTe and high luminescence CdTe/CdS quantum dots: The effect of ligands. Journal of Colloid and Interface Science, Vol. 333, No. 2, pp. 690-698, ISS N 0021-9797 
Ma J.J.; Liang J.G. \& Han H.Y. (2010). Study on the Synchronous Interactions between Different Thiol-Capped CdTe Quantum Dots and BSA. Spectroscopy and Spectral Analysis, Vol. 30, No. 4, pp. 1039-1043, ISS N 1000-0593

Majumder M.; Karan S.; Chakraborty A.K. \& Mallik B. (2010). Synthesis of thiol capped CdS nanocrystallites using microwave irradiation and studies on their steady state and time resolved photoluminescence. Spectrochimica Acta Part A: Molecular and Biomolecular Spectroscopy, Vol. 76, No. 2, pp. 115-121, ISS N 1386-1425

Mekis I.; Talapin D.V.; Kornowski A.; Haase M. \& Weller H. (2003). One-pot synthesis of highly luminescent CdSe/CdS core-shell nanocrystals via organometallic and "greener" chemical approaches. Journal of Physical Chemistry B, Vol. 107, No. 30, pp. 7454-7462, ISS N 1520-6106

Merkoci A. (2009). Biosensing using nanomaterials, Wiley, ISB N 978-0-470-18309-0, New Jersey

Merkoci A.; Marcolino-Junior L.H.; Marin S.; Fatibello-Filho O. \& Alegret S. (2007). Detection of cadmium sulphide nanoparticles by using screen-printed electrodes and a handheld device. Nanotechnology, Vol. 18, No. 3, pp. ISS N 0957-4484

Michalet X.; Pinaud F.F.; Bentolila L.A.; Tsay J.M.; Doose S.; Li J.J.; Sundaresan G.; Wu A.M.; Gambhir S.S. \& Weiss S. (2005). Quantum dots for live cells, in vivo imaging, and diagnostics. Science, Vol. 307, No. 5709, pp. 538-544, ISS N 0036-8075

Mićić O.I. \& Nozik A.J. (2002). Chapter 5 - Colloidal quantum dots of III-V semiconductors. In: Nanostructured Materials and Nanotechnology, Hari Singh N., pp. 183-205, Academic Press, ISB N 978-0-12-513920-5, San Diego

Milne L.; Nicotera P.; Orrenius S. \& Burkitt M.J. (1993). Effects of Glutathione and Chelating Agents on Copper-Mediated DNA Oxidation: Pro-oxidant and Antioxidant Properties of Glutathione. Archives of Biochemistry and Biophysics, Vol. 304, No. 1, pp. 102-109, ISS N 0003-9861

Qian H.; Li L. \& Ren J. (2005). One-step and rapid synthesis of high quality alloyed quantum dots (CdSe-CdS) in aqueous phase by microwave irradiation with controllable temperature. Materials Research Bulletin, Vol. 40, No. 10, pp. 1726-1736, ISS N 00255408

Qian H.F.; Dong C.Q.; Weng J.F. \& Ren J.C. (2006). Facile one-pot synthesis of luminescent, water-soluble, and biocompatible glutathione-coated CdTe nanocrystals. Small, Vol. 2, No. 6, pp. 747-751, ISS N 1613-6810

Ryvolova M.; Chomoucka J.; Janu L.; Drbohlavova J.; Adam V.; Hubalek J. \& Kizek R. (2011). Biotin-modified glutathione as a functionalized coating for bioconjugation of CdTe-based quantum dots. Electrophoresis, Vol. 32, No. 13, pp. 1619-1622, ISS N 0173-0835

Saran A.D. \& Bellare J.R. (2010). Green engineering for large-scale synthesis of water-soluble and bio-taggable CdSe and CdSe-CdS quantum dots from microemulsion by double-capping. Colloids and Surfaces A: Physicochemical and Engineering Aspects, Vol. 369, No. 1-3, pp. 165-175, ISS N 0927-7757

Saran A.D.; Sadawana M.M.; Srivastava R. \& Bellare J.R. (2011). An optimized quantum dotligand system for biosensing applications: Evaluation as a glucose biosensor. 
Colloids and Surfaces A: Physicochemical and Engineering Aspects, Vol. 384, No. 1-3, pp. 393-400, ISS N 0927-7757

Talapin D.V.; Lee J.S.; Kovalenko M.V. \& Shevchenko E.V. (2010). Prospects of Colloidal Nanocrystals for Electronic and Optoelectronic Applications. Chemical Reviews, Vol. 110, No. 1, pp. 389-458, ISS N 0009-2665

Thangadurai P.; Balaji S. \& Manoharan P.T. (2008). Surface modification of CdS quantum dots using thiols - structural and photophysical studies. Nanotechnology, Vol. 19, No. 43, pp. ISS N 0957-4484

Tian J.; Liu R.; Zhao Y.; Xu Q. \& Zhao S. (2009). Controllable synthesis and cell-imaging studies on CdTe quantum dots together capped by glutathione and thioglycolic acid. Journal of Colloid and Interface Science, Vol. 336, No. 2, pp. 504-509, ISS N 00219797

Tortiglione C.; Quarta A.; Tino A.; Manna L.; Cingolani R. \& Pellegrino T. (2007). Synthesis and biological assay of GSH functionalized fluorescent quantum dots for staining Hydra vulgaris. Bioconjugate Chemistry, Vol. 18, No. 3, pp. 829-835, ISS N 1043-1802

Wang X.; Lv Y. \& Hou X. (2011). A potential visual fluorescence probe for ultratrace arsenic (III) detection by using glutathione-capped CdTe quantum dots. Talanta, Vol. 84, No. 2, pp. 382-386, ISS N 0039-9140

Wang Y. \& Chen L. (2011). Quantum dots, lighting up the research and development of nanomedicine. Nanomedicine: Nanotechnology, Biology and Medicine, Vol. 7, No. 4, pp. 385-402, ISS N 1549-9634

Xing Y.; Xia Z.Y. \& Rao J.H. (2009). Semiconductor Quantum Dots for Biosensing and In Vivo Imaging. Ieee Transactions on Nanobioscience, Vol. 8, No. 1, pp. 4-12, ISS N 1536-1241

Xu W.B.; Wang Y.X.; Liang S.; Xu R.H.; Zhang G.X.; Xu F.H. \& Yin D.Z. (2008). Optimized synthesis and fluorescence spectrum analysis of CdSe quantum dots. Journal of Dispersion Science and Technology, Vol. 29, No. 7, pp. 953-957, ISS N 0193-2691

Xue M.; Wang X.; Wang H. \& Tang B. (2011). The preparation of glutathione-capped CdTe quantum dots and their use in imaging of cells. Talanta, Vol. 83, No. 5, pp. 16801686, ISS N 0039-9140

Ying J.Y.; Zheng Y.G. \& Selvan S.T. (2008). Synthesis and applications of quantum dots and magnetic quantum dots. In: Colloidal Quantum Dots for Biomedical Applications, Osinski M., Jovin T.M., Yamamoto K., pp. 86602-86602, Spie-Int Soc Optical Engineering, ISB N 0277-786X 978-0-8194-7041-6, Bellingham

Yuan J.; Guo W.; Yin J. \& Wang E. (2009). Glutathione-capped CdTe quantum dots for the sensitive detection of glucose. Talanta, Vol. 77, No. 5, pp. 1858-1863, ISS N 00399140

Yuan J.P.; Guo W.W.; Yin J.Y. \& Wang E.K. (2009). Glutathione-capped CdTe quantum dots for the sensitive detection of glucose. Talanta, Vol. 77, No. 5, pp. 1858-1863, ISS N 0039-9140

Zhang H.; Zhou Z.; Yang B. \& Gao M.Y. (2003). The influence of carboxyl groups on the photoluminescence of mercaptocarboxylic acid-stabilized CdTe nanoparticles. Journal of Physical Chemistry B, Vol. 107, No. 1, pp. 8-13, ISS N 1520-6106 
Zheng Y.G.; Gao S.J. \& Ying J.Y. (2007a). Synthesis and cell-imaging applications of glutathione-capped CdTe quantum dots. Advanced Materials, Vol. 19, No. 3, pp. 376-+, ISS N 0935-9648

Zheng Y.G.; Yang Z.C.; Li Y.Q. \& Ying J.Y. (2008). From glutathione capping to a crosslinked, phytochelatin-like coating of quantum dots. Advanced Materials, Vol. 20, No. 18, pp. 3410-+, ISS N 0935-9648

Zheng Y.G.; Yang Z.C. \& Ying J.Y. (2007b). Aqueous synthesis of glutathione-capped ZnSe and Zn1-xCdxSe alloyed quantum dots. Advanced Materials, Vol. 19, No. 11, pp. 1475-+, ISS N 0935-9648

Zhu J.-J.; Wang H.; Zhu J.-M. \& Wang J. (2002). A rapid synthesis route for the preparation of CdS nanoribbons by microwave irradiation. Materials Science and Engineering: B, Vol. 94, No. 2-3, pp. 136-140, ISS N 0921-5107 


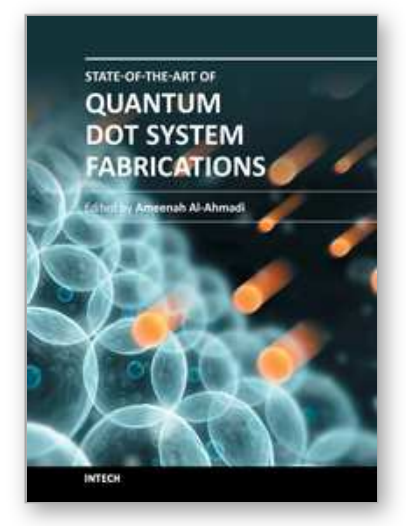

\author{
State-of-the-Art of Quantum Dot System Fabrications \\ Edited by Dr. Ameenah Al-Ahmadi
}

ISBN 978-953-51-0649-4

Hard cover, 172 pages

Publisher InTech

Published online 13, June, 2012

Published in print edition June, 2012

The book "State-of-the-art of Quantum Dot System Fabrications" contains ten chapters and devotes to some of quantum dot system fabrication methods that considered the dependence of shape, size and composition parameters on growth methods and conditions such as temperature, strain and deposition rates. This is a collaborative book sharing and providing fundamental research such as the one conducted in Physics, Chemistry, Material Science, with a base text that could serve as a reference in research by presenting up-todate research work on the field of quantum dot systems.

\title{
How to reference
}

In order to correctly reference this scholarly work, feel free to copy and paste the following:

Jana Chomoucka, Jana Drbohlavova, Petra Businova, Marketa Ryvolova, Vojtech Adam, Rene Kizek and Jaromir Hubalek (2012). Synthesis of Glutathione Coated Quantum Dots, State-of-the-Art of Quantum Dot System Fabrications, Dr. Ameenah Al-Ahmadi (Ed.), ISBN: 978-953-51-0649-4, InTech, Available from: http://www.intechopen.com/books/state-of-the-art-of-quantum-dot-system-fabrications/synthesis-ofglutathione-coated-quantum-dots

\section{INTECH}

open science | open minds

\section{InTech Europe}

University Campus STeP Ri Slavka Krautzeka 83/A 51000 Rijeka, Croatia Phone: +385 (51) 770447

Fax: +385 (51) 686166 www.intechopen.com

\section{InTech China}

Unit 405, Office Block, Hotel Equatorial Shanghai No.65, Yan An Road (West), Shanghai, 200040, China 中国上海市延安西路65号上海国际贵都大饭店办公楼 405 单元 Phone: +86-21-62489820

Fax: +86-21-62489821 
(C) 2012 The Author(s). Licensee IntechOpen. This is an open access article distributed under the terms of the Creative Commons Attribution 3.0 License, which permits unrestricted use, distribution, and reproduction in any medium, provided the original work is properly cited. 